\title{
Barriers and Challenges of Female Adult Students Enrolled in Higher Education: A Literature Review
}

\author{
Xi $\operatorname{Lin}^{1}$ \\ ${ }^{1}$ Department of Educational Foundations, Leadership, and Technology, Auburn University, AL, USA \\ Correspondence: Xi Lin, Department of Educational Foundations, Leadership, and Technology, Auburn \\ University, AL, 36849, USA. E-mail: xilin@auburn.edu
}

Received: March 21, 2016

Accepted: April 6, 2016

Online Published: May 5, 2016

doi:10.5539/hes.v6n2p119

URL: http://dx.doi.org/10.5539/hes.v6n2p119

\begin{abstract}
The present study is a review of the literature concerning the barriers and challenges of female adult students enrolled in colleges and universities in the United States. Findings indicated that the commitments of multiple roles, lower level of self-confidence, and insufficient family and social support were the most significant variables related to the barriers and challenges of this population. Suggestions and implications of assisting this student group are discussed. The purpose of the current study is to raise people's awareness and to understand the difficulties female adult students endure. It is also expected that family, peers, schools, and communities will offer more help to this special student group.
\end{abstract}

Keywords: barriers, challenge, female adult students, nontraditional students, higher education

\section{Introduction}

Adult students, also known as "nontraditional students", "re-entry students", "returning students" (Benshoff \& Lewis, 1992) are defined as adults who return to school full- or part-time while maintaining responsibilities such as employment, family, and other responsibilities of adult life (Cross, 1980). They are often at least one-year away between high school and college (Dill \& Henley, 1998). In addition, this population usually defined as over the age of 25 (e.g., Klein, 1990; Krager, Wrenn, \& Hirt, 1990; Padula, 1994; Roehl \& Okun, 1984; Scott, Burns, \& Cooney, 1996). Early studies mentioned that from one-third to one-half of all college students are identified as nontraditional students and over $50 \%$ of all graduate students are over 30 years of age (Aslanian \& Brickell, 1980; Elson, 1992). Over the past decades, the number of adult students is increasing rapidly. Researchers described this student group as "...the fastest-growing segment of all the population groups in higher education" (Brazzile, 1989, p. 116). U.S. Department of Education (2014) reported that in fall 2013, there were 17.5 million undergraduate students and 2.9 million post-baccalaureate (graduate) students attending degree-granting postsecondary institutions in America. Among them, 31.2\% were students who were age 25 and older. Furthermore, among the adult student population, $61.3 \%$ of them were female nontraditional students. This report mirrors early studies that nontraditional female students have become the fastest growing population in colleges and universities (Carney-Crompton \& Tan, 2002; Scott, Burns, \& Cooney, 1996).

Besides being students, nontraditional students usually have multiple roles such as parents, spouses, employees, etc. Female nontraditional students, compared to men, experienced competing pressure of child care, financial, and school responsibilities (Bauer \& Mott, 1990). The additional responsibilities would bring a variety of barriers and challenges to female adult students, which would influence their academic experience. Despite many studies investigated issues of female nontraditional students, the majority of the research is relevant to psychological issues such as anxiety, depression, along with others. Meanwhile, the psychological issues are often caused by challenges which may come from family, peers, and schools. As a result, there is a need to examine what has been investigated in order to further understand the research being done on this subject. Therefore, the current study aims to review literature associated to the primary barriers and challenges of female nontraditional students enrolled in higher education in the United States. The key research question guiding the review of the literature was: what are the major barriers and challenges experienced by female adult students enrolled in colleges and universities in the United States? 


\section{Strategy of Literature Review}

A systematic search of articles was conducted in several online databases-Educational Resources Information Center (ERIC), ProQuest Education Journals, PsycINFO, and PsycARTICLES. The following key terms were used while searching: female adult student(s), female nontraditional student(s), barrier(s), challenge(s), issue(s), adult student(s), and nontraditional student(s). Articles chosen for review were subject to the following criteria:

1) the reviewed articles are peer-reviewed and full text;

2) materials used in the review included studies that identify their subjects as female adult students or learners, female nontraditional students or learners, and adult students or learners;

3 ) articles included in the review should include some form of formal learning experiences in degree- or certificate-granting educational programs;

4) the search limiters used were data range from 1970 to 2015.

Moreover, books and literature reviews relevant with the research topic were used to complement the study.

\section{Findings from the Literature Review}

In general, the research on barriers and challenges of female adult students enrolled in higher education in the United States is at a developing stage. Much of the research considered adult students as a whole group by mixing both genders. In addition, among the limited number of studies focusing on female adult students, most of them aimed attention at motivators of returning to school or psychological issues of this population. In addition, compared with strategies of recruiting this population and coping with their psychological issues, methods to solve their challenges while studying on campus have drawn less attention. Nonetheless, the literature points to several primary challenges that could be informative for those who have adult female students in their classroom or as their consultants and mentees, to better understand this particular group of students.

Table 1. Categories of literature review

Categories Literature Review

Studies of Adult Students

(both genders) (e.g., Agar, 1990; Bauer \& Mott, 1990; Bell, 2003; Benshoff \& Lewis, 1992; Benshoff, 1992, 1993; Chartrand, 1990; Compton, Cox, \& Laanan, 2006; Crawford, 2004; Cross, 1980; Dill \& Henley, 1998; Ely, 1997; Huston-Hoburg \& Strange, 1986; Justice \& Dornan, 2001; Kasworm, 2003; Kennedy, 2003; Klein, 1990; Krager, Wrenn, \& Hirt, 1990; Lin \& Wang, 2015; Lundberg, 2003; Mallinckrodt \& Leong, 1992; McGivney, 2004; Muench, 1987; Puryear, 1988; Thon, 1984; Yarbrough \& Schaffer, 1990)

Studies of Female Adult Students (e.g., Anderson \& Miezitis, 1999; Backels \& Meashey, 1997; Carney-Crompton \& Tan, 2002; Coker, 2003; Furst, 1991; Home, 1993, 1997; Jackman, 1999; Jacobs \& King, 2002; King \& Bauer, 1988; Kirk \& Dorfman, 1983; Leavitt, 1989; Novak \& Thacker, 1991; Padula, 1994; Plageman \& Sabina, 2010; Quimby \& O’Brien, 2004, 2006; Roehl \& Okun, 1984; Schliebner, 1990; Scott, Burns, \& Cooney, 1996)

\subsection{Multiple Roles}

According to aforementioned research, adult students often maintain responsibilities such as employment, family, and other responsibilities of adult life (Cross, 1980). Muench (1978) mentioned that "Both [sexes] have difficulties juggling the role of student, worker, and family member" (p. 10). For female adult students, the primary challenge is to balance their multiple roles with the student role. They often occupy a great number of characters such as mothers, spouses/partners, employees, and community members (Chartrand, 1990; Home, 
1993, 1997; Huston-Hoburg \& Strange, 1986; Padula, 1994). As a result, their lifestyles are broader and more complex than their traditional counterparts (King \& Bauer, 1988), and they often have less time in doing extra school activities.

Nontraditional female students must balance school with employment, family, and financial responsibilities (Ely, 1997), which usually leads to time constrains. Jacobi (1987) discovered that female adult students had significantly more time constrains and role conflicts than their traditional counterparts. Among their many responsibilities, family commitment is the major challenge, especially for those with younger children. Kirk and Dorfman (1983) indicated that women with younger children had a highest level of pressure in their student roles. Caring for children usually needs considerable demands on time and energy, so that would influence female adult students' abilities and confidence to pursue an education (Quimbly \& O'Brien, 2004). Quimbly and O'Brien (2004) also mentioned that child-care responsibilities usually lead to a limited flexibility and would restrict their abilities to look for tutoring services or participate in group projects outside of class time.

In addition, other studies revealed that increases in roles, demands, and time conflicts were related with higher stress, anxiety, and depression for female adult students (Backels \& Meashey, 1997; Leavitt, 1989; Mallinckrodt \& Leong, 1992; Puryear, 1988; Roehl \& Okun, 1984). As a result, family responsibilities and commitments with the demands of academia would create more barriers and challenges to academic success for the nontraditional female students (Anderson \& Miezitis, 1999; Novak \& Thacker, 1991; Padula, 1994), and family variables are usually the reason that lead to the incomplete education for this population (Leavitt, 1989; Schliebner, 1990).

\subsection{Level of Self-Confidence}

To adult learners, the commitment to the student role would increase personal distress and they would have a negative emotional state if the student's self-evaluation did not meet the normative concept of a good student (Chartrand, 1990). Generally, nontraditional students have a clear goal and strong motivation when they re-enter higher education programs (e.g., Compton, Cox, \& Laanan, 2006). Early studies found that nontraditional students, both male and female, performed at a higher academic level than their younger counterparts (e.g., Carney-Crompton \& Tan, 2002). However, due to the many responsibilities outside of class, this group of students often lack the confidence in their academic ability and are less satisfied with their academic performance. Novak and Thacker (1991) investigated perceived satisfaction and role strain in nontraditional students and discovered that though $68 \%$ of the participants felt above average satisfaction in the student role, $85 \%$ felt strained. Their primary pressure comes from the conflicting time demands and anxieties about their academic ability.

Aging is another trigger that leads to adult learners' lower level of self-confidence in learning. It is believed that people's ability to learn is declined slowly and slightly after the age of 25 . Though early research revealed that the decline was the speed of learning instead of the intellectual power (Knowles, 1980), this stereo type often leads to the insufficient confidence among nontraditional students, especially for female adult students. Chartrand (1990) indicated that nontraditional female students often underestimate their skills and ability to succeed in colleges and universities. Similarly, Furst (1991) revealed that female adult students were usually self-doubting and ambivalent about taking college courses, and they have a higher test anxiety than their traditional counterparts (Yarbrough \& Schaffer, 1990). A recent study, which examined the experiences of African American female adult students in higher education also demonstrated that this group of students often had higher anxiety about their ability to do college work after many years away from school, and they frequently worried about whether they were able to keep up with traditional students (Coker, 2003).

\subsection{Family and Social Support}

Agar (1990) suggested that nontraditional students had gaps between their earlier school experiences and the university environment in the areas of institutional size, teaching styles, individualized attention, educational resources, standards for academic performance, socioeconomic necessities and expectations, and peer group supports. Women adult students face similar issues and may not receive much endorsement and support from family and community members (Jackman, 1999). As a result, the insufficient support they obtain may be a considerable reason that contributes to their lower level of self-confidence in academia.

Family support plays a significant role for female adult learners towards their academic experience. Since this student group reports family commitments as a major reason for not completing their degrees (McGivney, 2004), whether they get support from family would affect their decisions and process of continuing an education. In other words, a lack of support from spouses/partners and/or other family members would impede female adult students' educational process (e.g., Jacobs \& King, 2002; Kasworm, 2003; Leavitt, 1989; McGivney, 2004). Plageman and Sabina (2010) examined the relationship between family members and female adult students 
found that among their family of origin, mothers played the most significant supportive roles for female adult students to attend and persist in pursing higher education, as well as future achievements; while among their current family members, support from both spouses/partners and children were reported important for women adult students related to their academic experience. Some women consider pursing higher education would benefit themselves and their entire family (Coker, 2003). Similarly, Lin and Wang's (2015) study found that female adult students re-entered schools for the reason that they intended to catch up with other family members or to build a role model for their children. As a result, support from family would bring motivation and encouragement to female adult students during their path of pursing education.

Social support from faculty and peers would also affect both male and female adult students' academic experience and may predict satisfaction in the student role (Kirk \& Dorfman, 1983; Petersen \& Ebata, 1987; Petersen et al., 1991; Rice et al., 1993; Sands \& Richardson, 1984). Lundberg (2003) described that due to the off-campus responsibilities, adult students often have fewer campus peers with whom they could focus on conversations associated with educational topics. What's more, nontraditional students may experience generation gaps while communicating with younger students. Ouimby and O'Brien (2006) further suggested that female adult students face challenges when they re-enter into the college environment as learners and interacting with peers who are usually younger and have different values and priorities. The gap with younger traditional counterparts often make female adult learners feel marginalized and excluded from campus life (Padula, 1994). Moreover, the quality of relationship between nontraditional female students and their instructors would affect their academic experience (Coker, 2003). Different than younger students in terms of their ability to manage time limitations, aforementioned research indicated that female adult students may need more flexible schedules. Therefore, whether their instructors understand their needs and are willing too ffer assistance have a significant influence on their study.

\section{Discussions and Implications}

In sum, the commitments of multiple roles, lower level of self-confidence, and insufficient family and social support for female adult students would generate higher level of stress, anxiety, and others than their male peers as well as traditional counterparts. Furthermore, those stressors may put this population at a higher risk for dropping out of school. Therefore, it is necessary for female adult students to build self-confidence and obtain external support. Adult learners have been educated through their life experiences (Crawford, 2004), and their life experiences would in turn bring values to their study and learning since they already have a large knowledge base. Kennedy (2003) indicated that past experiences and practical knowledge can be a handicap in acquiring new knowledge. As a result, adult students, both male and female, should establish and nurture their self-confidence during their process of pursuing education.

It is also necessary for family, peers, and universities to help this particular student group. Getting enough support is significant to nontraditional female students. Support from family, peers, schools, along with others would provide adult women students secure attachment, confidence in managing the student role, and trustworthy relationships (Ouimby \& O'Brien, 2006). They may become more positive and confident, as well as more likely to conquer other academic challenges. In addition, whether adult women students are able to balance child-caring and school work would influence both their life and academic satisfaction (Ouimby\& O'Brien, 2006). Therefore, support from family and community members is significant. This group of students may have extra time to complete school activities and may have less stressors if their spouses/partners are willing to take family responsibilities when they are busy with student work. Moreover, it would be helpful if their siblings, other relatives, or any members from the community would like to give a hand for occasional child-caring.

In addition, it is important for instructors to work closely with this student population. Instructors play important roles in assisting adult women students both in and outside the classroom. Firstly, instructors could assist adult women students to reach their educational goals by designing syllabus with flexible due dates and project expectations. They could also combine assignments that fit the needs for adult women students and associated to their life events or experiences. Moreover, instructors may play vital roles in building the bridge to connect both traditional students and nontraditional women students. They may consider to assign a certain group work or project combined students from both groups. In addition, instructors could invite and encourage female adult students to share their life experiences towards a special topic. In this way, not only women adult learners could build a good rapport and get involved with the class, younger students also have an opportunity to gain practical knowledge from real life examples.

Aforementioned research described that the campus environment including institutional size, educational resources, standards for academic performance and so on are new for re-entering nontraditional students (Agar, 
1990), hence female adult students not only need assistance in building self-confidence, but also with acquiring and refreshing their study skills, as well as managing their time and other resources on campus (Benshoff, 1993). Meanwhile, since campus peers play important roles in successful learning experience in college for traditional students (Astin, 1993; Pascarella \& Terenzini, 2005), it would be helpful if schools offer tutors for adult students with their academic assignments and school lives. Tutoring assistance maynot only assist in establishing confidence for female adult students towards their academic performance, but could also help them get connected with more students and resources around campus. In this way, this student population would get used to campus life and build peer relationships quickly and with more satisfaction.

Starting from early time, services that schools usually offered for adult students are counseling-and career-related (Thon, 1984). Benshoff and Lewis (1992) later described several services which may better meet adult students' needs such as to separate registration, advising, and orientation, to offer more evening and weekend courses, to provide special assistance with financial aid, and to train faculty and staff in order to meet the needs of this population. To be more specific, it is significant to train qualified staff to specially deal with female adult students since they confront barriers and challenges that differentiate them from male adult students (e.g., Bauer \& Mott, 1990). Therefore, special assistance should be offered to this particular student group such as strategies in balancing family and school work. Colleges and universities could also provide programs or courses such as first year seminar courses for both male and female adult students. In this way, this population would have more opportunities to learn and acquire knowledge as well as skills during their transitional semester or period, so that they may get a better preparation for their future study and campus lives.

\section{Limitations and Suggestions}

This review identified three major barriers and challenges for female adult students enrolled in higher education. However, limitations existed in the literature. Firstly, the majority of the literature used in this review is from early period due to the limited numbers of latest studies towards this research topic. As a result, there is a need to conduct research about barriers and challenges for current female adult students in order to update the literature. Secondly, this study introduced general issues for female adult students enrolled in higher education in the United States, it would be profound to separate this population into different education levels (i.e., undergraduate programs, master programs, doctoral programs) to further identify whether they face different barriers and challenges. Finally, the subjects in most of the literature that used were female adult students enrolled in higher education in the U.S. Therefore, adult women students in other countries may endure diverse difficulties. In addition, international adult women students studied in the U.S. would confront specific issues that local adult women students may not. As a consequence, it is meaningful to investigate barriers and challenges among different female adult student groupsin future research.

\section{References}

Agar, D. (1990). Non-traditional students: Perceptions of problems which influence academic success. Higher Education, 19, 435-454. http://dx.doi.org/10.1007/BF00137007

Anderson, B., \& Miezitis, S. (1999). Stress and life satisfaction in mature female graduate students. Initiatives, 5, $33-43$.

Aslanian, C. B., \& Brickell, H. M. (1980). Americans in transition: Life changes as reasons for adult learning. New York: College Entrance Examination Board.

Astin, A. W. (1993). What matters in college?: Four critical years revisited (Vol. 1). San Francisco: Jossey-Bass.

Backels, S., \& Meashey, L. (1997). Anxiety, depression and the 4.0: Brief therapy with high-achieving, nontraditional female students. Journal of College Student Psychotherapy, 12, 45-56. http://dx.doi.org/10.1300/J035v12n01_05

Bauer, D., \& Mott, D. (1990). Life themes and motivations of reentry students. Journal of Counseling and Development, 68, 555-560. http://dx.doi.org/10.1002/j.1556-6676.1990.tb01410.x

Bell, J. A. (2003). Statistics anxiety: The nontraditional student. Education, 124(1), 157.

Benshoff, J. M. (1993, November). Educational opportunities, developmental challenges: Understanding nontraditional college students. Paper presented at the Annual Conference of the Association for Adult Development and Aging, New Orleans, LA.

Benshoff, J. M., \& Lewis, H. A. (1992). Nontraditional college students (Report No. EDO-CG-92-16). Washington, DC: Office of Educational Research and Improvement. 
Brazziel, W. F. (1990). Older students. In A. Levine, \& Associates (Eds.), Shaping higher education's future: Demographic realities and opportunities, 1990-2000. San Francisco: Jossey-Bass.

Carney-Crompton, S., \& Tan, J. (2002). Support systems, psychological functioning, and academic performance of nontraditional female students. Adult Education Quarterly, 52(2), 140-154. http://dx.doi.org/10.1177/0741713602052002005

Chartrand, J. M. (1990). A causal analysis to predict the personal and academic adjustment of nontraditional students. Journal of Counseling Psychology, 37(1), 65-73. http://dx.doi.org/10.1037/0022-0167.37.1.65

Coker, A. D. (2003). African American Female Adult Learners: Motivations, Challenges, and Coping Strategies. Journal of Black Studies, 33(5), 654-674. http://dx.doi.org/10.1177/0021934703033005007

Compton, J. I., Cox, E., \& Laanan, F. S. (2006). Adult learners in transition. New directions for student services, 2006(114), 73-80. http://dx.doi.org/10.1002/ss.208

Crawford, D. L. (2004). The role of aging in adult learning: Implications for instructors in higher education. New $\begin{array}{llll}\text { Horizons } & \text { for } & \text { Learning. } & \text { Retrieved }\end{array}$ http://education.jhu.edu/PD/newhorizons/lifelonglearning/higher-education/implications/

Cross, K. P. (1980). Our changing students and their impact on colleges: Prospects for a true learning society. The Phi Delta Kappan, 61(9), 627-630.

Dill, P. L., \& Henley, T. B. (1998). Stressors of college: A comparison of traditional and nontraditional students. The Journal of Psychology, 132(1), 25-32. http://dx.doi.org/10.1080/00223989809599261

Elson, J. (1992). Campus of the future. Time, 139(15), 54-58.

Ely, E. E. (1997, April). The non-traditional student. Paper presented at the American Association of Community Colleges annual conference, Anaheim, CA.

Furst, T. C. (1991). Going back to school: Women's reentry student experience (Doctoral dissertation, Cornell University, 1991). Dissertation Abstracts International, 54(12), 1389A.

Home, A. (1993). The juggling act: The multiple role woman in social work education. Canadian Social Work Review, 10(2), 141-156.

Home, A. (1997). Learning the hard way: Role strain, stress, role demands, and support in multiple-role women students. Journal of Social Work Education, 33, 335-347.

Huston-Hoburg, L., \& Strange, C. (1986). Spouse support among male and female returning adult students. Journal of College Student Personnel, 27(5), 388-394.

Jackman, M. K. (1999). When the person becomes professional: Stories from reentry adult women learners about family, work, and school. Composition Studies, 27(2), 53-67.

Jacobi, M. (1987). Stress among re-entry women students: A contextual approach. San Diego, CA: Association for the Study of Higher Education.

Jacobs, J. A., \& King, R. B. (2002). Age and college completion: A life-history analysis of women aged 15-44. Sociology of Education, 75(3), 211-230. http://dx.doi.org/10.2307/3090266

Justice, E. M., \& Dornan, T. M. (2001). Metacognitive Differences between Traditional-Age and Nontraditional-Age College Students. Adult Education Quarterly, 51(3), 236-249. http://dx.doi.org/10.1177/074171360105100305

Kasworm, C. E. (2003). Setting the stage: Adults in higher education. In D. Kilgore, \& P. J. Rice (Eds.), Meeting the special needs of adult students. New Directions for Student Services (Vol. 102, pp. 3-10). San Francisco, CA: Jossey-Bass. http://dx.doi.org/10.1002/ss.83

Kennedy, R. C. (2003). Applying principles of adult learning. FBI Law Enforcement Bulletin, 72(4), 1-5.

King, P. M., \& Bauer, B. A. (1988). Leadership issues for nontraditional-aged women students. New Directions for Student Services, 1988(44), 77-88. http://dx.doi.org/10.1002/ss.37119884409

Kirk, C. F., \& Dorfman, L. T. (1983). Satisfaction and role strain among middle-age and older reentry women students. Educational Gerontology: An International Quarterly, 9(1), 15-29. http://dx.doi.org/10.1080/0380127830090102

Klein, J. D. (1990). An analysis of the motivational characteristics of college reentry students. College Student Journal, 24(3), 281-286. 
Knowles, M. S. (1980). The modern practice of adult education. Chicago: Follet Publishing Company.

Krager, L., Wrenn, R., \& Hirt, J. (1990). Perspectives on age differences. New Directions for Student Services, 51, 37-47. http://dx.doi.org/10.1002/ss.37119905105

Leavitt, R. S. (1989). Married women returning to college: A study of their personal and family adjustments. Smith College Studies in Social Work, 59(3), 301-315. http://dx.doi.org/10.1080/00377318909517361

Lin, X., \& Wang, C. H. (2015). Factors that Affect Returning to Graduate School for International and American Adult Learners. Institute for Learning Styles Journal, 1, 40-53.

Lundberg, C. A. (2003). The influence of time-limitations, faculty, and peer relationships on adult student learning: A causal model. Journal of Higher Education, 665-688. http://dx.doi.org/10.1353/jhe.2003.0045

Mallinckrodt, B., \& Leong, F. T. (1992). Social support in academic programs and family environments: Sex differences and role conflicts for graduate students. Journal of Counseling and Development, 70, 716-723. http://dx.doi.org/10.1002/j.1556-6676.1992.tb02154.x

McGivney, V. (2004). Understanding persistence in adult learning. Open Learning, 19(1), 33-46. http://dx.doi.org/10.1080/0268051042000177836

Mucench, K. E. (1987, October). A comparative study of the psychosocial needs of adult men and women students in an adult degree program. Paper presented at the annual meeting of the American Association for Adult and Continuing Education, Washington, DC.

Novak, M., \& Thacker, C. (1991). Satisfaction and strain among middle-aged women who return to school: Replication and extension of findings in a Canadian context. Educational Gerontology, 17(4), 323-342. http://dx.doi.org/10.1080/0360127910170403

Padula, M. A. (1994). Reentry women: A literature review with recommendations for counseling and research. Journal of Counseling and Development, 73, 10-16. http://dx.doi.org/10.1002/j.1556-6676.1994.tb01703.x

Pascarella, E. T., \& Terenzini, P. T. (2005). In K. A. Feldman (Ed.), How college affects students (Vol. 2). San Francisco, CA: Jossey-Bass.

Petersen, A. C., \& Ebata, A. T. (1987). Developmental transitions and adolescent problem behavior: Implications for prevention and intervention. In K. Hurrelmann, \& F. X. Kaufmann (Eds.), Social intervention: Potential and constrains (pp. 167-184). New York: de Gruyter.

Petersen, A. C., Kennedy, R. E., \& Sullivan, P. A. (1991). Coping with adolescence. In M. E. Colten, \& S. Gore (Eds.), Adolescent stress: Causes and consequence (pp. 93-110). New York: Aldine de Gruyter.

Plageman, P., \& Sabina, C. (2010). Perceived Family Influence on Undergraduate Adult Female Students. The Journal of Continuing Higher Education, 58(3), 156-166. http://dx.doi.org/10.1080/07377363.2010.491768

Puryear, A. D. (1988). Understanding the needs of adult students. Community Services Catalyst, 18(4), 13-16.

Quimby, J. L., \& O’Brien, K. M. (2006). Predictors of Well-Being among Nontraditional Female Students with

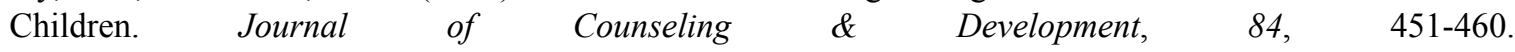
http://dx.doi.org/10.1002/j.1556-6678.2006.tb00429.x

Quimby, J. L., \& O'Brien, K. M. (2004). Predictors of Student and Career Decision-Making Self-Efficacy among Nontraditional College Women. The Career Development Quarterly, 52(4), 323-339. http://dx.doi.org/10.1002/j.2161-0045.2004.tb00949.x

Rice, K. G. (1992). Separation-individuation and adjustment to college: A longitudinal study. Journal of Counseling Psychology, 39(2), 203. http://dx.doi.org/10.1037/0022-0167.39.2.203

Roehl, J. E., \& Okun, M. A. (1984). Depression symptoms among women reentering college: The role of negative life events and family social support. Journal of College Student Personnel, 25(3), 251-254.

Sands, R. G., \& Richardson, V. (1984). Educational and mental health factors associated with the return of mid-life women to school. Educational Gerontology, 10(2), 155-170. http://dx.doi.org/10.1080/0380127840100206

Schliebner, C. T. (1990). Returning adult women students: The effects of role strain and perceived spouse support on the intent to remain in college (Doctoral dissertation, Syracuse University, 1990). Dissertation Abstracts International, 50, Z5055. 
Scott, C., Burns, A., \& Cooney, G. (1996). Reasons for discontinuing study: The case of mature age female students with children. Higher Education, 31(2), 233-253. http://dx.doi.org/10.1007/BF02390446

Thon, A. J. (1984). Responding to the non-academic needs of adult students. NASPA journal, 21(4), 28-35.

U.S. Department of Education. (2014). Total fall enrollment in degree-granting postsecondary institutions, by attendance status, sex, and age: Selected years, 1970 through 2023. Retrieved from http://nces.ed.gov/programs/digest/d13/tables/dt13_303.40.asp

Yarbrough, D. W., \& Schaffer, J. L. (1990). A comparison of school-related anxiety experienced by nontraditional versus traditional students. College Student Journal, 24(1), 81-90.

\section{Copyrights}

Copyright for this article is retained by the author, with first publication rights granted to the journal.

This is an open-access article distributed under the terms and conditions of the Creative Commons Attribution license (http://creativecommons.org/licenses/by/3.0/). 